\title{
The impact of Internet on the artist reputation
}

\section{Castelló, Daniel; De la Poza, Elena; Guadalajara, Natividad}

Center of Economic Engineering, Faculty of Business and Management, Universitat Politècnica de València, Spain.

\begin{abstract}
This work analyzes the relationship between the digital information provided by the search engine Google on the Internet and the volume of sales or revenues in the art market in order to quantify the variable artist's reputation. In particular, the usefulness of digital media information is analyzed to interpret past sales in the art market or, conversely, to estimate future sales in the short term. Finally, we study the ability of digital information to explain the volume of activity (number of lots sold) or what is the same the degree of liquidity of the secondary market of artworks.
\end{abstract}

Keywords: Art market; Internet; artist's reputation; lots, revenues. 


\section{Introduction}

In the art market all agents (artists, galleries, auction houses, dealers...) involved make use of the double use of Internet as a channel of information and communication, and to support their activity.

Internet has supported and dynamic the secondary art market, promoting its growth through online auctions. Major international auction houses such as Christie's and Sotheby's expose their collections online before each session, or even carry out some of these sessions online (Adam, 2002), and their purchases are collected in large digital databases, providing transparency to the art market (Beaux Arts Magazine, 2007).

In fact, recent studies such as Dass et al. (2011) and Schlaegel (2015) analyze changes in auction prices of works of art in the field of online auctions; those researches identify which variables influence in order to improve artworks pricing models and generate bidding strategies for the buyer of works of art in the secondary market.

But not only the secondary market for art has been affected by the Internet, the artists use it to inspire and develop their creative abilities (Hansen, 2006), as well as to promote and sell their work from their own blogs, from social networking (MySpace, Facebook, LinkedIn) (Wikberg, 2014) or from websites like eBay or Craiglist (Grant, 2008; Canals-Cerdá, 2014). This continuous and sustained development has meant that these sites acquire the role of a source of information for analyzing market prices of artworks (Deng et al, 2014).

Studies on valuation of works of art, both in the academic field as in traditional media (newspapers, magazines, etc.) are numerous. In most of these, the value of the artworks is estimated by building mathematical models focused on their physical and artistic characteristics, the place of sale of the work, the date of sale, the nationality of the artist and the artists 'number of exhibitions. On contrast, the artist's reputation which is difficult to quantify (Ursprung and Wiermann, 2008) has not been included in these analysis, but clearly influences the value of works of art and, therefore, in the art market. Authors like Anderson (2004) analyzes the reputation of the museum through variables results or "outcomes" resulting from the activity of the museum, such as the number of results that appear in the Google search engine, the number of visits to the museum, or the economic impact of the museum measured through the turnover generated by tickets to the museum.

Caballer and De-la-Poza (2005), Guadalajara and De-la-Poza (2007) and De-la-Poza, et al., (2009) included in their valuation models the artist's reputation, measured by the media digital information, and studying the influence of turnover and average prices of the auctioned works of each artist in those media. 
In this work we analyze the relationship between the digital information provided by Google and the volume of sales or revenues in the art market in order to quantify the variable artist's reputation.

In particular, the usefulness of digital media information is analyzed to interpret past sales in the art market or, conversely, to estimate future sales in the short term. Finally, we analyze the ability of digital information to explain the volume of activity (number of lots sold) or what is the same the degree of liquidity of the secondary market of artworks.

\section{Methods}

\subsection{Sources of information}

Search engine Google was selected as primary source of digital information. Its selection was based on the volume of queries conducted throughout 2006 by Internet users worldwide. In 2015 Google continues ranking the list of the most used search engine with a market share of $75.2 \%$ followed by Yahoo with a market share of $10.4 \%$.

Also, the database Artprice was employed as a source of information on the art market. Artprice provides information about the sale prices of works traded in the international auction houses since 1997. The choice of ArtPrice compared to other similar databases is due to the extensive information provided on each work and artist as well as the rapid updating of information and, most importantly, by the possibility of online research.

\subsection{Database construction}

The collection of data was carried out in several stages:

Firstly, we classify the top-100 artists in terms of the turnover reached by their works of art sold at international auction houses in the period from 1997 to 2015. It is a sufficiently long period of time to make a selection of artists with greater presence in the market and comprises the whole economic cycle, (economic expansion and recession).

However, the top 100 ranking varies from year to year changing the composition of the sample, with the exception of Picasso who always was ranked first throughout the period. Thus, looking for maintaining the sample of artists constant, we selected those artists who ranked the top 100 for at least 9 years of our period of study but also had at least 10 works of art sold each semester. These criteria were applied with the dual purpose of choosing figures of great relevance in the market but with a continuous presence in it.

Then, the number of results obtained in Google for each artist was quantified (January 2007; December 2015 and again in January 2016). The search was performed entering the name and surname of the artist, date of birth and death in quotes. This search system has 
given rise to the cybermetric variables, "GoogleC" followed by the reference year. The aim of this type of search is to ensure that we only take into account those results that are directly related to the artist.

\section{Methodology}

In accordance with the study by De la Poza, et al., (2009), we want to test the following hypotheses:

1. The results (number of results) for each artist in Google in the year $(n+1)$ are related to the turnover reached by the artist in the art market art at year $n$.

2. The volume of sales in the art market in the year $n$ is related to short-term results in Google in the year $n+1$.

3. Finally, it is tested if the number of lots sold on the art market is related to the results on Google.

The methodology used has been the simple regression analysis. The purpose of this analysis is to investigate and explain the linear relationship established between a dependent variable (in this case the turnover in the art market), and an independent variable (number of results in Google); adjusted- $\mathrm{R}^{2}$ coefficient measures the goodness of fit of the proposed models.

\section{Results}

The sample of artists is collected in Table 1, determining their position in the ranking in 2006 and 2015. All artists remained in the top 100 in 2015 with the exception of Edgar Degas, Kees Van Dongen and Maurice de Vlaminck. 
Castelló, D.; De la Poza, E.; Guadalajara, N.

Table 1. Sample of artists and their ranking position in 2006 and 2015.

\begin{tabular}{lcc}
\hline \multicolumn{1}{c}{ Artist } & 2006 & 2015 \\
\hline Picasso, Pablo & 1 & 2 \\
Warhol, Andy & 2 & 1 \\
Monet, Claude & 14 & 7 \\
Kooning, Willem de & 4 & 16 \\
Chagall, Marc & 6 & 23 \\
Basquiat, Jean-Michel & 37 & 11 \\
Léger, Fernand & 27 & 35 \\
Lichtenstein, Roy & 10 & 14 \\
Miró, Joan & 22 & 25 \\
Matisse, Henri & 9 & 28 \\
Renoir, Auguste & 11 & 36 \\
Dongen, Kees van & 23 & 154 \\
Giagometti, Alberto & 28 & 8 \\
Modigliani, Amedeo & 5 & 18 \\
Degas, Edgar & 31 & 101 \\
Pissarro, Camille & 24 & 49 \\
Calder, Alexander & 32 & 27 \\
Fontana, Lucio & 17 & 26 \\
Cézanne, Paul & 18 & 74 \\
Richter, Gerhard & 21 & 4 \\
Twombly, Cy & 120 & 12 \\
Vlaminck, Maurice de & 41 & 261 \\
\hline
\end{tabular}

The regression models were computed, (Table 2). The table shows the regression models to value the turnover of the artists selected for each year (2006, 2007, 2014 and 2015) throughout the collected cybermetric variable GoogleC at different years.

Table 2. Regression Models

\begin{tabular}{ccccccc}
\hline Function & $\mathrm{a}$ & $\mathrm{p}$-value & $\mathrm{b}$ & $\mathrm{p}$-value & Adjusted $\mathrm{R}^{2}$ & Durbin-Watson \\
\hline $\mathrm{F} 2006=\mathrm{f}($ GoogleC2007 $)$ & $30,766,933.72$ & 0 & 7.76 & 0 & 0.70 & 1.95 \\
$\mathrm{~F} 2007=\mathrm{f}($ GoogleC2007 $)$ & $56,381,249.98$ & 0.001 & 6.08 & 0.007 & 0.27 & 1.6 \\
$\mathrm{~F} 2015=\mathrm{f}($ GoogleC2016) & $6,411,786.09$ & 0.917 & 450.11 & 0.027 & 0.18 & 1.08 \\
$\mathrm{~F} 2015=\mathrm{f}($ GoogleC2015 $)$ & $16,584,411.14$ & 0.778 & 431.23 & 0.031 & 0.17 & 1.1 \\
$\mathrm{~F} 2014=\mathrm{f}($ GoogleC2015 $)$ & $10,210,560.81$ & 0.831 & 313.67 & 0.051 & 0.14 & 1.45 \\
\hline
\end{tabular}

By the models obtained it is remarkable to highlight the loss of explanation of the cyber metric variable over time. Thus, the variable "GoogleC2007" explained 70\% variability of the turnover of the group of selected artists in 2006, while the turnover of the same group of artists in 2015 was explained by $18 \%$ by the "GoogleC" variable in 2016. 
Also, it is important to highlight the importance that acquires the cyber metric variable "GoogleC2015" and "GoogleC2016" in the art market turnover. Thus, each result in the search engine "GoogleC2016" increases the 2015 turnover by 450 Euros. In fact, the coefficient of the variable "GoogleC2007" was 6.08, meaning that each additional result in the search engine Google increased turnover 6.08 Euros in 2006, while in 2015 the variable "GoogleC" contributed to the marginal increase in turnover in 2015 431.23 Euros.

One of the reasons that explain the increase in the value of the coefficient "GoogleC" in recent years (2015 and 2016), is the smallest number of results recorded by that search engine. The reason lies in the advances implemented by Google in capturing information available on the Internet. This has meant that for every artist the number of results has reduced considerably provided that both the name is included, as the years of birth and death, ("GoogleC"). This results in the mathematical expression that relates terms (turnover and number of citations), the slope coefficient and also value of the variable "GoogleC (term b) take high values.

Finally table 2 shows the results for testing the third hypotheses about the capacity of the cyber metric information to measure the number of lots sold (L) in the art market:

Table 3. Regression Models

\begin{tabular}{ccccccc}
\hline Function & $\mathrm{a}$ & $\mathrm{p}$-value & $\mathrm{b}$ & $\mathrm{p}$-value & Corrected $^{2}$ & $\begin{array}{c}\text { Durbin- } \\
\text { Watson }\end{array}$ \\
\hline $\mathrm{L}(2007)=\mathrm{f}($ GoogleC2007) & 155,82 & 0.009 & 0.0000401 & .000 & 0.54 & 2.27 \\
$\mathrm{~L}(2015)=\mathrm{f}($ GoogleC2015) & $-355,68$ & 0.235 & 0.003 & 0.006 & 0.29 & 1.28 \\
\hline
\end{tabular}

As table 3 shows the explanatory power of the cyber metric information to measure the liquidity of the market drops over time.

\section{Conclusions}

This study presents a useful methodology for the assessment and quantification of the artist's reputation. In previous work (De la Poza, et al., 2009) was shown that there was a relationship between the information provided by search engines on the Internet and the volume of revenue in the art market, both in past and future in the short term.

As presented, the paradigm today is different; the results show how the explanatory power of the cyber metric variables is less at present than in the past. Thus, the explanatory power of the model valuation has dropped from values close to $70 \%, 30 \%$ and $46 \%$ for the cases studied in the years 2006 and 2007 to models whose explanatory power is below $20 \%$ and even very close to zero. 
The same result was found when explaining the market liquidity, measured by the number of lots sold by the artists and the same cyber metric variables. One of the causes of the decline of explanatory power of the turnover by the cyber metric variables is the variation in the number of results. This is the case of Google, which from 2007 onwards has made continuous improvements to its search algorithm, and updating Caffeine in 2009, apart from reducing the search speed considerably increased refining searches, offering better results and better indexed temporarily.

In 2006 and 2007, the relationship between sales in the art market and cyber metric information in the Google search engine is greater when it comes to explaining past sales that future, suggesting that this information digital is able to collect a greater extent what happened in the market in the short term to estimate future sales.

In summary, these results open a path to new research to assess the artist through its impact on cyber metrics, and use the means of digital information to analyze the art market in long term.

\section{References}

Artprice.com: les raisons d'un succès. (2007). In Beaux arts magazine(276), 68-69.

Adam, G. (2002). "The opportunity to find bargains?". Art newspaper, 13(121), 33.

Anderson, M. L. (2004). Metrics of Succes in Art Museums. The Getty Leadership Institute. United States.

Caballer, V., \& De la Poza, E. (2005). Modelos econométricos para la valoración de obras pictóricas. VIII Congreso Internacional Cultura Europea. Universidad de Navarra, 110.

Canals Cerdá, J. (2012). The value of a good reputation online: an application to art auctions. Journal of cultural economics, 36, 67-85.

Dass, M., Jank, W., \& Shmueli, G. (2011). Maximizing bidder surplus in simultaneous online art auctions via dynamic forecasting. International Journal of Forecasting, 27, 1259-1270.

De la Poza, E., \& Guadalajara, N. (2007). The Influence of the Net-Metric and BiblioMetric Variables on the Top Artists. Estudios de Economía Aplicada, 25(1), 5-22.

De la Poza, E., Guadalajara, N., \& Moya, I. (2009). El rol de los medios de información digitales en los precios en el mercado del arte. El profesional de la información, 18(4), 382-388.

Deng, S., Mitsubuchi, T., \& Sakurai, A. (2014). Stock price shange rate prediction by utilizing social network activities. The Scientific World Journal, 14.

Grant, D. (2008). The internet art market. American artist, 72, 76. 
Guadalajara, N., \& De la Poza, E. (2007, abril). The influence of the netmetric and bibliometric variables on the top artists of the international art market. Estudios de economía aplicada, 25(1), 5-22.

Hansen, G. (2006, May). I'm feeling lucky: using Google to break a creative slump. Craft reports, 32, 36 .

Schlaegel, C. (2015). Understanding individuals' initial and continued use of online auction marketplaces. A meta-analysis. Management Research Review, 38(8), 855-907.

Ursprung, H. W., \& Wiermann, C. (2008). Reputation, Price, and Death: An Empirical Analysis of Art Price Formation. CESifo Working Paper(2237).

Wikberg, E., \& Strannegard, L. (2014). Selling by Numbers: The quantification and marketization of the Swedish Art World for Contemporary Art. Organizational Aesthetics, 3(1), 19-41. 